\title{
MODELING OF PLASMA CHEMICAL DEPOSITION AND DEGRADATION OF SILICON THIN FILMS
}

\author{
Valeria V. Krzhizhanovskaya ${ }^{1,2}$, Peter M. A. Sloot ${ }^{1}$ and Yuriy E. Gorbachev ${ }^{2}$ \\ ${ }^{1}$ Section Computational Science, University of Amsterdam \\ Kruislaan 403, NL-1098 SJ Amsterdam, The Netherlands. \\ $\{$ valeria, sloot\}@science.uva.nl \\ ${ }^{2}$ St. Petersburg State Polytechnic University \\ Polytechnicheskaya 29, St. Petersburg 195251, Russia. \\ \{lera,gorbachev\}@csa.ru
}

Thin silicon films are important semiconductor material widely used in modern microelectronics and solar cells. One of the technologies employed for industrial production of these films is plasma enhanced chemical vapor deposition (PECVD). Modeling and simulation of this industrially important technology is essential for optimizing physical and chemical parameters, reactive chamber geometry and operating regimes of the installation, in order to reduce the costs of film production and to provide a better growth rate and film quality in terms of layer composition and homogeneity. For the latter, spatial processes (convection, diffusion, heat transfer, chemical transformations and plasma non-uniformity), as well as the variation of system behavior in time, play a decisive role. We have developed a 3D transient multiphysics multiscale model taking into account all relevant chemical kinetics, plasma physics and transport processes that occur in the bulk of a PECVD reactor and on the surface of the growing film [Krzhizhanovskaya, V.V., Zatevakhin, M.A., Ignatiev, A.A., Gorbachev, Yu.E., Goedheer, W.J. and Sloot, P.M.A., In Proceedings of the 5th International Bi-Annual ASME/JSME Symposium on Computational Technologies for Fluid/Thermal/Structural/ Chemical Systems with Industrial Applications, ASME PVP-vol. 491-2, 59-68, 2004]. In addition to that we have built an efficient problem solving environment for scientists studying PECVD processes and end-users working in chemical industry [Krzhizhanovskaya, V.V., Sloot, P.M.A. and Gorbachev, Yu.E., Simulation: Transactions of the Society for Modeling and Simulation International, vol. 81, No. 1, 77-85, 2005].

One of the most challenging and least studied topics in modeling a time-dependent film deposition is the process of film degradation at the end of the production cycle, when the plasma is 'switched off' and the inflow of the source gases is stopped. Experimental analysis of processes occurring at this stage is very difficult because the processes of plasma recombination, radicals' diffusion towards the surface and their attachment to the film, are much faster than the time needed for film characterization. Moreover, the measurements of the composition and homogeneity are usually done 'off-line', after the film is taken out of the reactive chamber. In order to study the film degradation processes computationally, we carried out a series of simulation experiments varying the basic physical and chemical parameters (pressure, temperature, inflow rate, raw mixture composition and chemical reaction rates), as well as the moments in time when the finishing stages occur (plasma switch-off, gas inflow and heating shut-down).

In this paper we briefly introduce the previously developed 3D model of plasma chemical deposition emphasizing the dissipative nature of the processes; then we present the latest development for modeling the film degradation processes; describe the problem solving environment created to provide distributed parallel multitask simulation and visualization on computer Grids; and finally present the simulation results.

The model presented is an extension of the 1D [Gorbachev, Yu.E., Zatevakhin, M.A., Krzhizhanovskaya, V.V. and Shveigert, V.A., Technical Physics, vol. 45, No 8, 1032-1041, 2000], 
2D [Krzhizhanovskaya, V.V., Zatevakhin, M.A., Ignatiev, A.A., Gorbachev, Y.E. and Sloot, P.M.A., Lecture Notes in Computer Science, vol. 2328, 879-888, 2002] and 3D [Krzhizhanovskaya, V.V., Zatevakhin, M.A., Ignatiev, A.A., Gorbachev, Yu.E., Goedheer, W.J. and Sloot, P.M.A., In Proceedings of the 5th International Bi-Annual ASME/JSME Symposium on Computational Technologies for Fluid/Thermal/Structural/ Chemical Systems with Industrial Applications, ASME PVP-vol. 491-2, 59-68, 2004] models previously developed by the authors, with a new description of chemical processes taking into account oligomer formation [Gorbachev, Yu.E., Technical Physics, in press, 2005.]. The model is based on the numerical solution of the full Navier-Stokes equations for transient laminar flows of viscous compressible multi-component mixtures of chemically reacting gases. The boundary conditions take into account temperature jumps, as well as molecular slipping and sticking processes on the walls. For simulation of capacitively coupled plasma discharge, a fluid model [Nienhuis, G.J. and Goedheer, W.J., Plasma Sources Sci. Technol., v. 8, 295-298, 1999] was used. The electron and ion continuity equations were solved consistently with the Poisson equation for the electric field distribution.

We developed a "Virtual Reactor", generic problem solving environment [Krzhizhanovskaya, V.V., Sloot, P.M.A. and Gorbachev, Yu.E., Simulation: Transactions of the Society for Modeling and Simulation International, vol. 81, No. 1, 77-85, 2005] with an advanced interaction capabilities integrating the basic modules for reactor geometry design, computational mesh generation, plasma, flow and chemistry simulation, as well as editors of chemical reactions and gas properties, databases, pre- and postprocessors, advanced multimodal visualization modules, Web-interfaces and a Grid portal. The first steps in integrating distributed resources through Grid technology promise efficient utilization of the computing power.

The model developed has shown a good ability to predict the main characteristics of PECVD processes [Krzhizhanovskaya, V.V., Zatevakhin, M.A., Ignatiev, A.A., Gorbachev, Yu.E., Goedheer, W.J. and Sloot, P.M.A., In Proceedings of the 5th International Bi-Annual ASME/JSME Symposium on Computational Technologies for Fluid/Thermal/Structural/ Chemical Systems with Industrial Applications, ASME PVP-vol. 491-2, 59-68, 2004]. The Virtual Reactor allowed us to study the film degradation processes and to find the featuring trends in system response to the variation of physical and chemical parameters and the operating actions. We were able to indicate the mechanisms responsible for the irreversible deterioration of film homogeneity and degradation of the layer composition at the finishing stage of the film production process.

Acknowledgements

The research was conducted with financial support from the Dutch National Science Foundation and the Russian Foundation for Basic Research within the projects No 047.016.007 and 047.016.018, and with partial support from the CrossGrid EU project IST-2001-32243 (www.eu-crossgrid.org) and from the Virtual Laboratory for e-Science project (www.vl-e.nl).

\section{References}

1. Krzhizhanovskaya, V.V., Zatevakhin, M.A., Ignatiev, A.A., Gorbachev, Yu.E., Goedheer, W.J. and Sloot, P.M.A., In Proceedings of the 5th International Bi-Annual ASME/JSME Symposium on Computational Technologies for Fluid/Thermal/Structural/ Chemical Systems with Industrial Applications, ASME PVP-vol. 491-2, 59-68, 2004

2. Krzhizhanovskaya, V.V., Sloot, P.M.A. and Gorbachev, Yu.E., Simulation: Transactions of the Society for Modeling and Simulation International, vol. 81, No. 1, 77-85, 2005

3. Gorbachev, Yu.E., Zatevakhin, M.A., Krzhizhanovskaya, V.V. and Shveigert, V.A., Technical Physics, vol. 45, No 8, 1032-1041, 2000

4. Krzhizhanovskaya, V.V., Zatevakhin, M.A., Ignatiev, A.A., Gorbachev, Y.E. and Sloot, P.M.A., Lecture Notes in Computer Science, vol. 2328, 879-888, 2002

5. Gorbachev, Yu.E., Technical Physics, in press, 2005.

6. Nienhuis, G.J. and Goedheer, W.J., Plasma Sources Sci. Technol., v. 8, 295-298, 1999 